\title{
Editorial: COCOON 2012 Special Issue
}

\author{
Joachim Gudmundsson · Julián Mestre · Taso Viglas
}

Received: 19 May 2014 / Accepted: 21 May 2014 / Published online: 13 June 2014

(C) Springer Science+Business Media New York 2014

This special issue contains a selection of seven papers from the 18th Annual International Computing and Combinatorics Conference (COCOON), held during August 20-22, 2012, in Sydney Australia. The conference program featured 50 presentations chosen from 121 submissions, covering a wide range of topics related to theoretical aspects of computing. This is reflected by the seven papers selected for the special issue whose topics range from clustering to circuit lower bounds. The papers were invited based on their evaluation by the COCOON 2012 program committee, and went through the standard rigorous refereeing process of Algorithmica before being accepted to this special issue.

We wish to thank the authors for submitting their papers to the special issue, the referees for their thorough reviews and the journal for giving us the opportunity to compile this special issue. We hope that the readers will find the papers in it both interesting and enjoyable.

Guest Editors

\footnotetext{
J. Gudmundsson $(\varangle) \cdot$ J. Mestre · T. Viglas

University of Sydney, Sydney, NSW, Australia

e-mail: joachim.gudmundsson@sydney.edu.au

J. Mestre

e-mail: julian.mestre@sydney.edu.au

T. Viglas

e-mail: taso.viglas@sydney.edu.au
} 